\title{
FATORES CRÍTICOS DE SUCESSO PARA A IMPLEMENTAÇÃO DA MANUFATURA ENXUTA
}

\section{CRITICAL SUCCESS FACTORS TO IMPLEMENT LEAN MANUFACTURING}

\author{
Marcelo Augusto Oliveira da Justa \\ Universidade Federal do Amazonas - UFAM/FT - Manaus/AM - Brasil \\ marcelo.justa@bol.com.br
}

\begin{abstract}
Resumo
O objetivo da pesquisa é identificar, classificar e sintetizar os fatores críticos de sucesso (FCS) que impedem as organizações de replicar e implementar o Sistema Toyota de Produção, também chamado de Manufatura Enxuta (ME) ou Lean Manufacturing. Inicialmente, é desenvolvido uma breve revisão da literatura sobre os conceitos relacionados ao tema. Logo após, apresenta-se uma análise e classificação dos vários FCS que dificultam a implementação da ME. Trata-se, portanto, de uma pesquisa bibliográfica nos diversos trabalhos publicados e que fazem referências aos entraves encontrados durante o processo de introdução da ME. A pesquisa revela que há uma grande diversidade de observações em relação aos fatores críticos da ME nas organizações, o que causa uma dispersão de ideias sobre qual preparação é realmente necessária para implementar com sucesso a ME. As conclusões demonstram que apesar dessa diversidade de observações há pontos comuns nos fatores constatados entre os autores pesquisados, mesmo em empresas de setores diferentes. Portanto, as informações antes dispersas nas diversas literaturas são agora condensadas, a fim de orientar as organizações sobre quais os FCS que as organizações devem dar foco para que a ME evolua de forma consistente e sustentável.
\end{abstract}

Palavras-chave: fatores críticos de sucesso; sistema toyota de produção; manufatura enxuta.

\section{Introdução}

O termo Lean, que significa "enxuto", foi cunhado no livro "A Máquina que Mudou o Mundo". O livro trata de um amplo estudo sobre o Sistema Toyota de Produção (STP). Esse termo foi popularizado no ocidente por Womack, Jones e Roos (1992), os quais relatam o resultado de uma pesquisa realizada pelo Massachusetts Institute of Technology (MIT) sobre uma descrição abrangente de todo o modelo de gestão da Toyota, compreendendo o desenvolvimento de produtos, o gerenciamento de suprimentos, as relações com os consumidores, o atendimento dos pedidos desde a matéria prima até a produção e o gerenciamento de toda a empresa.

A definição mais clássica do Lean Manufacturing, ou Manufatura Enxuta (ME), consiste na aplicação de práticas que visam à identificação e eliminação de desperdícios do sistema produtivo, bem como a busca incessante por melhor qualidade e custos mais baixos. 
De acordo com Womack e Jones (2004), desperdício significa qualquer atividade que absorve recursos, mas que não agrega valor. Valor significa a capacidade de oferecer um produto ou serviço no momento certo, a um preço adequado e conforme definido pelo cliente. A base da ME, uma vez eliminado os desperdícios, é reduzir os custos de produção e maximizar a satisfação do cliente, ou seja, do valor agregado.

Segundo Porter (1999), essa iniciativa das empresas em melhorar a qualidade com custos menores, é forçada pelas exigências dos clientes e pela competitividade global, pois, para competir com eficácia neste ambiente globalizado, as empresas devem continuamente inovar e buscar aprimoramento contínuo das vantagens competitivas.

É neste caminho que a Toyota desponta como liderança global na conquista da competitividade em obter melhores resultados com menor custo, pois, transformou a operação em um diferencial competitivo e estratégico baseado em ferramentas e métodos de melhoria continua da manufatura. Vale ressaltar que apesar de originalmente ter sido concebido como essencialmente práticas de manufatura, a ME também têm sido gradualmente copiada em outras áreas diferente da produção.

Neste contexto, desde a publicação do estudo do MIT, o Lean tem sido o modelo de gestão escolhido pelas empresas que tentam implantar em suas fábricas as mesmas práticas diferenciadas do STP, a fim de atingir os mesmos níveis de desempenho da montadora japonesa. Portanto, é a partir do sucesso e resultados obtidos pela Toyota que estudos são realizados com o intuito de entender os Fatores Críticos de Sucesso (FCS) da ME.

Rockart (1979) introduziu o conceito de FCS na hierarquia das ferramentas de gestão. Segundo o autor, definem-se como algumas áreas de atividade chave, cujos resultados favoráveis são absolutamente necessários para que os gestores possam atingir os objetivos. O mesmo ressalta que tão importante quanto a determinação das metas que o gerente deseja atingir, é a determinação de forma consciente e explícita da estrutura básica das variáveis que podem influenciar o sucesso ou o fracasso no alcance das metas, sendo que estas variáveis são os FCS.

No estudo, os FCS da ME podem ser entendidos como os fatores necessários para garantir a preparação adequada do ambiente organizacional, indispensável para o êxito na introdução da ME. Entretanto, para a temática principal desse trabalho, admite-se a existência de inúmeros fatores identificados nas literaturas sobre a ME.

É devido a este cenário que se faz necessário a análise bibliográfica dos FCS observados, a fim de permitir uma organização da dispersão encontrada na literatura e assim classificar os fatores que realmente são considerados decisivos para se desenvolver o ambiente da ME.

Thompson Jr. e Strickland III (2004) enfatizam a necessidade de redução da lista dos inúmeros FCS existentes. O objetivo é eliminar os fatores de pequena relevância e assim poder dar 
foco e atenção para aqueles fatores realmente cruciais na preparação do ambiente organizacional.

Na realidade, o que se espera com esse estudo não é eliminar alguns FCS em detrimento de outros, mas sim classificá-los e sintetizá-los de tal forma que as organizações possam reconhecer os FCS que realmente são relevantes para a preparação do ambiente da ME, necessário para uma implementação sustentável. O benefício em sintetizar os FCS está no foco das ações necessárias, poupando os desperdícios de recursos durante o processo de implementação (ROCKART, 1979).

Machado et al (2007) ressaltam que as empresas devem dedicar especial atenção aos FCS, a fim de garantir desempenho superior e alcançar o sucesso. No entanto, a realidade da ME é de uma dificuldade generalizada nas empresas que tentam replicar o modelo. A falta de foco e um caminho determinado acabam por desperdiçar o tempo das organizações nas sucessivas tentativas e erro durante o processo de implementação da ME.

No final, o que restam são tentativas e erros frustrados sem que haja um caminho sistematizado a seguir e assim obter melhorias nos processos, na eficiência e nos resultados. Infelizmente, a realidade é que a preparação adequada do ambiente organizacional em relação aos FCS é desprezada, mesmo com o grande número de estudos já realizados.

O ambiente organizacional de uma empresa, principalmente relacionada à implantação de uma nova filosofia de trabalho, vai muito além do simples repasse de informações, normas e procedimentos que todos devem seguir a partir do lançamento de um programa que se deseja implementar. Trata-se de um processo lento que deve ser construído e sedimentado passo a passo, pois envolve mudanças de hábitos, pensamentos, sentimentos e percepções que antes estavam inseridos no dia a dia das pessoas e que fazem parte da identidade da empresa.

Esse ajuste na cultura organizacional começa a partir da criação de um ambiente favorável para que a mudança ocorra, pois mesmo a mais elaborada estratégia de negócio e o mais moderno aparato tecnológico não conseguem alavancar resultados positivos sem que haja o engajamento dos seus colaboradores.

Ré et al (2007) afirmam que as empresas devem articular uma relação de confiança e compreensão entre os membros da organização, a fim estimulá-los a trocar informações e criar ambientes organizacionais que facilitem a socialização do conhecimento, pré-requisitos para a criação de um ambiente de aprendizagem.

Segundo Mello Cordeiro (2007), há fatores que pertencem à cultura da Toyota e do Japão que são os principais responsáveis pelo sucesso da mesma e que não podem ser replicados para empresas ocidentais, pois, constituem-se recursos e competências totalmente distintivos em virtude de sua ambigüidade causal e dependência da trajetória de aprendizado.

Essa afirmação não é conclusiva, pois há outras empresas japonesas que também têm ficando atrás dos padrões Toyota. Vale lembrar que o STP foi introduzido pela Toyota em todo o 
mundo, inclusive na fábrica dos Estados Unidos. Também no Pólo Industrial de Manaus há exemplos de empresas japonesas e coreanas que conseguem obter resultados até melhores que suas matrizes no país de origem.

Em relação à necessidade de desenvolver uma cultura com mentalidade Lean, não há como negar a demanda atual pela implementação da ME. Neste contexto, implementar com sucesso e de forma sustentável tem sido o grande desafio das organizações. No entanto, o que se constata é o impressionante $90 \%$ de insucesso nas tentativas das organizações que fracassam nessa jornada (WOMACK, 2007).

Há na literatura inúmeros caminhos que tentam indicar os fatores críticos para as empresas que desejam replicar o modelo do STP. Contudo, essa dispersão de observações acaba por confundir a real direção a seguir. Desta forma, esse estudo vem contribuir com a resposta para a seguinte questão: quais os fatores críticos de sucesso que realmente são necessários para que as empresas possam replicar o STP?

\section{Metodologia da pesquisa}

Em relação à metodologia aplicada, essa pesquisa se caracteriza quanto aos fins como exploratória, uma vez que busca sistematizar conhecimento que ainda não se encontra suficientemente integrado. Quanto aos meios, é uma pesquisa bibliográfica, porém composta de análises críticas e inspirada na vivência de autores que já realizaram estudos sobre o assunto em questão.

Nesse contexto, registro que este estudo procura avançar na abrangência dos FCS em relação à filosofia do STP. Desta forma, procura-se focar nos FCS identificados nas principais literaturas que tratam da implementação da ME.

Em relação ao método aplicado para escolha das literaturas, procurou-se coletar livros e artigos que continham registros relevantes sobre os fatores críticos de sucesso da implementação da ME, STP ou Lean. O objetivo foi levantar o referencial teórico e bibliográfico necessário para embasar o estudo, sem perder o foco da pesquisa.

Para os artigos, adotaram-se dois critérios para a escolha das fontes bibliográficas. $\mathrm{O}$ primeiro foi o conceito Qualis da Coordenação de Aperfeiçoamento de Pessoal de Nível Superior (CAPES). O objetivo é escolher os artigos com elevado padrão de excelência na qualidade da produção intelectual. Portanto, foram escolhidos apenas os artigos publicados em periódicos com avaliação igual ou superior ao Qualis B3.

Segundo a CAPES (2013), o Qualis é um conjunto de procedimentos utilizados para estratificar a qualidade da produção intelectual dos programas de pós-graduação. O Qualis afere a qualidade dos artigos e de outros tipos de produção, a partir da análise da qualidade dos veículos de 
divulgação, ou seja, os periódicos científicos. Essa análise segue uma régua de avaliação que são classificados nos seguintes indicativos da qualidade: A1, o mais elevado; A2; B1; B2; B3; B4; B5 e C - com peso zero.

O segundo critério foi à escolha de artigos que continham os relatos das experiências com os entraves observados durante o processo de implementação da ME. O objetivo é delimitar a quantidade de obras existente sobre o tema da ME, a fim de dar foco naquelas que realmente identificam os FCS com base em relatos experimentados.

Para as publicações em livros não há uma régua para avaliação da qualidade da produção intelectual, uma vez que não existem exemplos em outros países que classifiquem livros. Até o momento, não existem bases bibliométricas e indexadores consensuais equivalentes aos adotados para os periódicos. Na realidade, o que há atualmente é um processo ainda em construção para se estabelecer critérios e procedimentos para a qualificação dos livros, tal como acontece com os artigos (CAPES, 2013).

No entanto, para efeito de escolha dos livros a serem usados como fonte relevante para esse estudo, adotou-se quatro pré-requisitos próprios: (i) a obra deve ser um produto impresso ou eletrônico que possua um International Standard Book Number (ISBN), contendo no mínimo 50 páginas publicado por editora pública ou privada, associação científica e/ou cultural, instituição de pesquisa ou órgão oficial; (ii) o livro deve conter produção intelectual que esteja diretamente voltada para a área e tema aqui estudado; (iii) o livro deve possuir relevância temática para com o foco do estudo aqui realizado e (iv) o autor deve ser alguém reconhecido pela sua contribuição intelectual na área e tema da pesquisa.

Para este último, entre outros autores, também foi considerada a escolha de importantes "gurus" que escreveram livros sobre a ME ou STP, tais como: Ohno (1997), Shingo (1996), Imai (1996), Womack, Jones e Roos (2004), Liker (2005), Hines e Taylor (2000), entre outros.

Vale esclarecer que o ISBN é um sistema que normatiza e identificam numericamente os livros segundo o título, o autor, o país e a editora, individualizando-os inclusive por edição. $\mathrm{O}$ sistema é controlado pela Agência Internacional do ISBN, que orienta e delega poderes às agências nacionais. No Brasil, a Fundação Biblioteca Nacional representa a Agência Brasileira desde 1978, com a função de atribuir o número de identificação aos livros editados no país (AGÊNCIA BRASILEIRA DO ISBN, 2013).

Segundo Godinho Filho e Fernandes (2004), que também fazem uso do método de classificação em seus artigos, ressaltam que as classificações estão inseridas na atividade científica e que o conhecimento científico se baseia na classificação. Portanto, fazer uso dessa metodologia é perfeitamente viável para o conhecimento da problemática aqui estudada. 
Para Good (1965) apud Godinho Filho e Fernandes (2004), as classificações podem servir para os seguintes propósitos: i) conhecimento mental e comunicação; ii) descoberta de novo campo de pesquisa; iii) planejamento de estrutura organizacional ou estrutura de máquina; iv) lista de conferência; v) entretenimento. Em relação aos propósitos citados, a classificação utilizada nesse trabalho se encontra nos grupos (i) e (ii), o qual servirá para desenvolver o conhecimento sobre o tema Lean, além de pontos para serem estudados em futuras pesquisas.

\section{Identificação dos fatores críticos de sucesso}

\subsection{Artigos que registram os FCS da ME}

Seguindo os critérios mencionados na metodologia, a pesquisa bibliográfica identificou os seguintes artigos sobre os FCS da ME:

Walter e Tubino (2012) realizaram uma consulta bibliográfica nos anais do Encontro Nacional de Engenharia de Produção (ENEGEP), entre o período de 2001 e 2010. Nesse trabalho, os autores identificaram 28 artigos Qualis A2 que tratam da implantação da ME. Os mesmos constataram que as práticas mais utilizadas nos estudos de caso para implementar a ME estavam relacionadas à aplicação das equipes multifuncionais, da melhoria contínua e das técnicas e ferramentas Lean.

Tanaka, Muniz Jr e Faria Neto (2012), em seu artigo Qualis B3, realizaram uma pesquisa em um ambiente industrial e identificaram os seguintes FCS: a cultura de melhoria contínua; o comprometimento da alta administração; a liderança; o trabalho em equipe; a clareza dos papéis e responsabilidades; o aproveitamento do conhecimento e das experiências das pessoas; a sinergia das pessoas; o apoio das áreas de suporte; um projeto que contribua para o crescimento das pessoas; um projeto alinhado com as metas da organização; a definição do escopo do projeto; a determinação dos resultados esperados; a elaboração adequada de um cronograma; o controle regular das metas e a evolução das ações; a velocidade para a implementação das ações; e o controle da quantidade de projetos concorrentes com o uso dos mesmos recursos.

Segundo Spear e Bowen (1999), em seu artigo Qualis B2, a implementação do STP se baseia em algumas regras, dentre elas estão: todo o trabalho deve ser altamente especificado em relação ao conteúdo, seqüência, tempo e resultado desejado; qualquer melhoria deve ser realizada pelos envolvidos na atividade que está sendo melhorada.

Para Durán e Batocchio (2003), em seu artigo Qualis B3, existem critérios da norma SAE J4000 da Society for Automotive Engineers, intitulada 'Identificação e mensuração de melhores práticas na implementação de uma operação enxuta', que contribuem para que manufatura enxuta seja alcançada. A seção principal da norma apresenta 52 componentes divididos em 6 elementos e que avaliam o grau de implantação dos princípios de operações enxutas em uma empresa. 
Dentre os 6 elementos, destaca-se o elemento 1 (Ética e Organização) que analisa o reconhecimento e envolvimento da direção e alta gerência junto ao sistema e se as iniciativas disseminadas por estes estão sendo implementadas junto ao planejamento estratégico da organização e o elemento 2 (Pessoas e RH) que verifica o nível de participação de todos da organização para o sucesso do Sistema.

Lucato, Maestrelli e Vieira Jr, (2004), em seu artigo Qualis B2, também avaliam a norma destacando que para avaliar o grau de implementação da ME, a SAE J4000 define um peso de importância relativa para cada um. Do total de 100\% igual a 6 elementos, $25 \%$ é dado para o elemento 1 (Ética e Organização) e outros 25\% para o elemento 2 (Pessoas e RH), portanto, 50\% (metade) são designados para elementos relacionados ao envolvimento das pessoas para o sucesso da implementação do Lean.

Achanga et al (2006), em seu artigo Qualis B2, afirmam que em uma pesquisa realizada com pequenas e médias empresas do Reino Unido, analisou os fatores críticos de sucesso para implantação da produção enxuta e concluíram que a liderança, a cultura organizacional, as finanças e o conhecimento e habilidade estão entre esses fatores críticos.

Feitosa et al (2007), em seu artigo Qualis A2, concluem que mais que tecnologia, a Toyota valoriza pessoas, destacando a tomada de decisões conjuntas, centrada na localização das perdas.

Lorenzatto e Ribeiro (2007), em seu artigo Qualis A2, afirmam que a simples aplicação de técnicas e ferramentas relacionadas ao STP não é suficiente para tornar uma empresa enxuta. Para se atingir esse nível, é fundamental que todos que compõem o sistema compreendam a filosofia de eliminação dos desperdícios e estejam comprometidos com a satisfação plena dos clientes.

Mello (2007), em seu artigo Qualis A2, afirma que a aplicação dos princípios e técnicas da Produção Enxuta está relacionada à mudança de paradigma.

O autor também sinaliza que as empresas brasileiras não estão dispostas a fazer os investimentos necessários em capacitação de funcionários e aguardar o tempo para que os resultados apareçam. Portanto, acabam descontinuando ou deixando de implementar componentes essenciais alegando resultados insuficientes. Neste contexto, grande parte das dificuldades para implementar as técnicas e ferramentas do STP no Brasil, pode estar ligada á dificuldades de compreensão do significado da Produção Enxuta.

Schulz et al (2007), em seu artigo Qualis A2, destacam as relações entre a área fábrica, organização e cultura. Os mesmos afirmam que são evidencias da cultura o envolvimento dos empregados na gestão e implementação de melhorias no sistema de produção. Havendo clima, a fábrica e todos os aspectos relacionados serão potencializados.

Alves, Souza e Ferraz (2007), em seu artigo Qualis A2, identificaram os seguintes FCS: o compromisso da liderança com a implementação dos programas de melhoria; a motivação e o 
engajamento das pessoas; o trabalho em equipe e a capacitação para alcançar resultados; a constância de propósito, com foco nas metas; e a dedicação das pessoas nas atividades.

Quinhões e Torres Jr (2012), em seu artigo Qualis B1, realizaram uma entrevista com os gestores da empresa pesquisada, a fim de avaliar o processo de transformação para a empresa enxuta. Basicamente, as observações dos autores foram às seguintes: a expansão dos conceitos da filosofia ocorreu de forma conturbada devido à falta de compreensão básica dos novos procedimentos; houve grande resistência dos funcionários que não queriam sair da zona de conforto.

Os mesmos ressaltam que o sucesso da ME não está apenas no conhecimento ou aplicação das ferramentas, mas na perfeita imersão dos conceitos e na forma como esses estão alinhados com as metas estratégicas da organização.

Nogueira et al (2006), em seu artigo Qualis A1, destacam que o uso de indicadores de desempenho é um fator chave na implementação do sistema de produção enxuta. Os mesmos relatam que a participação dos níveis operacionais foi um dos fatores mais fortes para o sucesso da ME.

De acordo com Lima e Elias (2007), em seu artigo Qualis A2, o motivo do insucesso em replicar esse modelo está na tentativa das empresas em criar seus próprios sistemas de produção apenas com o foco em algumas ferramentas sem antes entender claramente os princípios do sistema e a filosofia. Eles ainda afirmam que nem sempre uma ferramenta utilizada em uma empresa fará com que se obtenham as mesmas melhorias em outra do mesmo porte e mesmo ramo de atuação, já que estas têm suas peculiaridades e métodos de gestão.

Godinho Filho e Fernandes (2005), em seu artigo Qualis B2, definem esses princípios como as ideias que norteiam uma ação ou decisão, isto é, os princípios representam o "o quê" deve ser atingido ou buscado. Já as ferramentas, são definidas como capacitadores, isto é, eles representam o “como" atingir um princípio.

Eles ainda alertam que há uma estreita relação entre princípios e capacitadores o que se torna imprudente separá-los, pois, para que os princípios sejam alcançados, é necessário concretizar os capacitadores. Desta forma, dar foco apenas na introdução de algumas ferramentas significará insucesso em replicar o STP.

Nesse contexto, a simples combinação dos princípios e os capacitadores podem ser receita de êxito na aplicação de grande variedade de situações e empresas. Entretanto, a realidade das empresas demonstra que também é necessário desenvolver a mentalidade, os valores e a disciplina, o que requer total envolvimento e entendimento por parte das pessoas em relação às essas ferramentas e princípios. 
Segundo Tubino et al (2008), em seu artigo Qualis A2, o sucesso e a sustentabilidade da ME vai muito além da disciplina em aplicar as ferramentas e técnicas, mas principalmente capacitação adequada das pessoas. O estudo dos autores constatou que a indústria analisada apresentava indicadores de prática muito abaixo do desempenho esperado.

\subsection{Livros que registram os FCS da ME}

Seguindo os critérios mencionados na metodologia, a pesquisa bibliográfica identificou os seguintes livros que registram os FCS da ME:

Segundo Shingo (1996), a Toyota levou mais de 20 anos para aprimorar o que hoje chamamos de Sistema Toyota de Produção. A boa notícia é que ele acalma a todos dizendo que outras organizações não precisam dos mesmos 20 anos para implementar o STP. Contudo, faz-se necessário que o sistema tenha tempo para adquirir consistência. O mesmo até apresenta um cronograma para a introdução do STP em 01 ano.

Corrêa e Corrêa (2004) também ratificam que a implantação da maioria das técnicas da Produção Enxuta requer um tempo de maturação.

Shingo ressalta que o STP necessita de um claro entendimento e empenho da alta gerência para promover as reformas necessárias. A importância da compreensão e o consentimento de todos são essenciais, especialmente as pessoas do chão de fábrica. Desta forma, esse seria o elemento chave que determinará o sucesso ou o fracasso para implementar o STP.

O autor relata os fatores básicos para a construção do STP. O mesmo propõe que os Sistemas Produtivos sejam projetados a partir de uma rede de processos e operações. Shingo destaca que é necessário estabelecer uma guerra sistemática as perdas, visando à redução dos custos, redução dos prazos de entrega, entrega assegurada, entrega dentro do prazo e qualidade assegurada dos produtos. Dentre as técnicas fundamentais que viabilizam o sucesso do STP, destaca-se a Troca Rápida de Ferramentas, a inspeção na fonte, a análise e engenharia de valor e o Kanban.

Taiichi Ohno, junto com Shigeo Shingo, é um dos principais "gurus" que dá base a pesquisa. Em seu livro intitulado 'O Sistema Toyota de Produção - além da produção em larga escala', o lendário Ohno relata toda a trajetória e processo de formação do STP. Dentre as várias técnicas e métodos aplicados, há uma mensagem que ecoa até hoje para as organizações que pretendem replicar o STP. Trata-se do refrão de que é preciso "criatividade diante da necessidade" (OHNO, 1997).

A frase tem um significado importante para aqueles que desejam implementar a ME. $\mathrm{O}$ fator crítico está em não copiar simplesmente aquilo que deu certo em outros lugares, mas sim entender o porquê deu certo, quais os princípios e técnicas pertinentes e como pode servir para a atual situação. 
A ordem então é empreender continuamente em esforços de inovação operacional.

Segundo Ohno (1997), o objetivo mais importante do STP é aumentar a eficiência da produção pela eliminação consistente e completa de desperdícios (perdas). Neste contexto, o sucesso do STP está em investir tempo no Gemba (termo japonês para o local de trabalho) e aprender a mapear as atividades que agregam valor, e as que não agregam valor, a fim de melhorar a qualidade dos processos e produtos, com custos mais baixos.

Para Ohno, o chão de fábrica é a principal fonte de informação da manufatura. Ele menciona um exemplo clássico sobre os procedimentos de trabalho que não podem ser escritos em uma escrivaninha. Há a necessidade de revisão e teste para que qualquer pessoa possa compreender de imediato.

Imai (1996) ressalta sobre a necessidade do envolvimento de todas as pessoas, do gerente ao colaborador do chão de fábrica. Deve-se dar especial atenção ao aperfeiçoamento de processos e orientações para melhorias contínuas que demandam menor investimento e tempo de implantação, além da motivação, comunicação, treinamento, trabalho em equipe, envolvimento e autodisciplina.

Womack, Jones e Roos (2004) relatam que o estudo das fábricas no qual se adotou a produção enxuta revelou que os trabalhadores reagem apenas quando existe senso de compromisso mútuo.

Liker (2005) relata 14 princípios que sustentam o STP, tais com: basear as decisões estratégicas em uma filosofia de longo prazo; criar um fluxo de processo contínuo para trazer os problemas à tona; usar sistemas puxados para minimizar estoques; nivelar carga de trabalho; construir uma cultura de parar e resolver problemas; padronizar as tarefas e capacitar os colaboradores; usar controle visual para que nenhum problema fique oculto; usar tecnologia confiável e que atenda os colaboradores e processos; desenvolver líderes que compreendam o trabalho, que vivam a filosofia e ensinem outros; desenvolver pessoas e equipes; desafiar fornecedores e parceiros a melhorar; ver por si mesmo para compreender a situação; tomar decisões por consenso e tornar-se uma organização de aprendizagem através da melhoria contínua.

Para o autor, a valorização da organização por meio do desenvolvimento de seus funcionários, é um dos principais princípios necessários para o êxito do STP. O mesmo enfatiza que um dos maiores desperdícios é não utilizar a criatividade das pessoas que trabalham na organização.

O mesmo também ressalta a possibilidade de utilizar uma variedade de ferramentas do STP e ainda assim estar seguindo apenas alguns princípios do Modelo Toyota, tendo como resultado "saltos" de curto prazo nas medidas de desempenho e que não serão sustentáveis. Por outro lado, uma organização que pratica com excelência todos os princípios do STP estará a caminho de uma vantagem competitiva sustentável.

Hines e Taylor (2000) sugerem que é preciso equipar os operários com "óculos de muda" 
(muda significa qualquer atividade que consome recursos sem agregar valor aos clientes), tornandoos aptos a enxergar as perdas. A ideia, em seguida, é criar uma cultura que os encoraje todos a eliminar as perdas, uma vez identificadas.

Slack, Chambers e Jonhston (2002) afirmam que para implantar da produção enxuta é necessário o envolvimento total das pessoas, uma vez que os empregados são treinados e motivados para assumir total responsabilidade pelo trabalham que realizam.

Ballé e Ballé (2007) relatam que a maioria das tentativas de implantar o Lean fracassa nas empresas porque não adianta somente adquirir o vocabulário, as ferramentas, princípios ou especialistas. É preciso, sobretudo, incorporar uma atitude Gemba para o sistema enxuto prosperar.

Côrrea e Gianesi (1993) enfatizam que a implantação do sistema Lean requer uma abordagem sistêmica na qual, uma série de aspectos da empresa é modificada.

Os autores também apontam que são necessários alguns pré-requisitos para implantar a ME, dentre eles: a mudança para a mentalidade enxuta; capacitação de operadores; ambiente de trabalho que favoreça a flexibilidade, comunicação e trabalho em equipe; conhecimento de processos e fluxos.

Mann (2010) afirma que o processo de implementação Lean necessita de um gerenciamento Lean. Em um sistema enxuto os resultados certamente importam, mas a abordagem para alcançá-los difere muito dos métodos convencionais de gestão. A diferença no sistema de gestão Lean é o foco no processo, bem como o foco em resultados. A premissa é a seguinte: deve-se começar a desenvolver um processo Lean que possa produzir resultados Lean. Se o processo tiver sido bem projetado e mantido, os resultados aparecerem.

O autor destaca que o sistema de gestão Lean é um elemento integrante do processo Lean. Se o processo fosse um sistema perfeito, seria sempre executado como foi projetado e sempre irá entregar resultados consistentes. Entretanto, um sistema no mundo real exige manutenção periódica para continuar a produzir resultados.

Vale lembrar que a complexidade aumenta quando as pessoas são inseridas nesse processo, pois as pessoas também necessitam de todo tipo de "manutenção" e atenção. Deixado o processo Lean à própria sorte, as pessoas podem modificar o processo de tal forma a ficar muito longe do projeto original. Desta forma, a disciplina é o outro fator relevante no processo Lean. Sem um alto grau de disciplina, a desordem se instala em curto espaço de tempo. Portanto, sem um sistema de gestão Lean adequado, a implementação da ME não prosperará.

\section{Classificação e sintetização dos FCS}

A pesquisa bibliográfica revelou que há uma diversidade de observações em relação aos fatores críticos da ME. É essa variedade de fatores que causam a dispersão das ideias sobre qual o 
caminho a seguir, bem como a preparação adequada para implementar a ME com sucesso. No entanto, os registros das observações identificadas demonstram que há uma similaridade nas constatações dos autores pesquisados.

Desta forma, os registros apresentam as condições necessárias para a classificação desses fatores, a fim de proporcionar às organizações a possibilidade de dar foco nos FCS que realmente determinam o caminho inicial a ser seguido rumo à evolução da ME.

A Figura 1 apresenta o resultado da classificação preliminar das observações constatadas. $\mathrm{O}$ resultado foi a classificação de 8 FCS, são eles: (1) Participação do nível operacional (trabalho em equipe); (2) Capacitação (Conhecimento, Habilidades, Atitudes); (3) Participação da alta administração (gestão participativa); (4) Aplicação das Técnicas e Ferramentas (melhoria contínua); (5) Identificar e Eliminar perdas e desperdícios (Gemba - processos); (6) Alinhamento com a Estratégia (objetivos, metas, ações, resultados); (7) Cultura Organizacional (filosofia e mudança de paradigma/mentalidade) e (8) Padronização das atividades, papéis, responsabilidades e disciplina.

Figura 1 - Classificação dos FCS da ME

\begin{tabular}{|c|c|c|c|c|c|c|c|c|}
\hline FATORES CRÍTICO DE SUCESSO (FCS) & (1) & (2) & (3) & (4) & (5) & (6) & (7) & (8) \\
\hline Womack, Jones \& Roos (1992) & $\mathrm{x}$ & & $\mathrm{x}$ & $\mathrm{x}$ & $\mathrm{x}$ & $\mathrm{x}$ & $\mathrm{x}$ & $\mathrm{x}$ \\
\hline Côrrea \& Gianesi (1993) & $\mathrm{x}$ & $x$ & & $\mathrm{x}$ & $\mathrm{x}$ & & $\mathrm{x}$ & \\
\hline Shingo (1996) & $\mathrm{x}$ & $\mathrm{x}$ & $\mathrm{x}$ & $\mathrm{x}$ & $\mathrm{x}$ & & $\mathrm{x}$ & $\mathrm{x}$ \\
\hline Imai (1996) & $\mathrm{x}$ & $x$ & $\mathrm{x}$ & $\mathrm{x}$ & $\mathrm{x}$ & & & $x$ \\
\hline Ohno (1997) & $\mathrm{x}$ & $\mathrm{x}$ & $\mathrm{x}$ & $\mathrm{x}$ & $\mathrm{x}$ & & $\mathrm{x}$ & $\mathrm{x}$ \\
\hline Spear \& Bowen (1999) & $x$ & & & & & & & $x$ \\
\hline Hines \& Taylor (2000) & & $\mathrm{x}$ & & & $\mathrm{x}$ & & $\mathrm{x}$ & \\
\hline Slack, Chambers \& Jonhston (2002) & $x$ & & $\mathrm{x}$ & & & & & \\
\hline Duran \& Batocchio (2003) & $\mathrm{x}$ & & $\mathrm{x}$ & & & $x$ & & \\
\hline Lucato, Maestrelli \& Vieira Jr (2004) & $\mathrm{x}$ & & $\mathrm{x}$ & & & & & \\
\hline Corrêa \& Corrêa (2004) & & & & & & & $\mathrm{x}$ & \\
\hline Liker (2005) & $\mathrm{x}$ & $\mathrm{x}$ & $\mathrm{x}$ & $\mathrm{x}$ & $\mathrm{x}$ & $\mathrm{x}$ & $\mathrm{x}$ & $\mathrm{x}$ \\
\hline Godinho Filho \& Fernandes (2005) & $\mathrm{x}$ & $\mathrm{x}$ & & $\mathrm{x}$ & & & & \\
\hline Achanga et al (2006) & & $\mathrm{x}$ & $\mathrm{x}$ & & & $x$ & $\mathrm{x}$ & \\
\hline Nogueira et al (2006) & $\mathrm{x}$ & & & & & $\mathrm{x}$ & & \\
\hline Feitosa et al (2007) & $\mathrm{x}$ & & $\mathrm{x}$ & & $\mathrm{x}$ & & & \\
\hline Ballé \& Ballé (2007) & & $\mathrm{x}$ & & $\mathrm{x}$ & $\mathrm{x}$ & & & \\
\hline Lorenzato \& Ribeiro (2007) & & & & $\mathrm{x}$ & $\mathrm{x}$ & & & \\
\hline Mello (2007) & & $\mathrm{x}$ & & $\mathrm{x}$ & & & & \\
\hline Schulz et al (2007) & $\mathrm{x}$ & & $\mathrm{x}$ & $\mathrm{x}$ & & & $x$ & \\
\hline Alves, Souza \& Ferraz (2007) & $\mathrm{x}$ & $\mathrm{x}$ & $\mathrm{x}$ & $\mathrm{x}$ & & $x$ & & $\mathrm{x}$ \\
\hline Lima \& Elias (2007) & & $\mathrm{x}$ & & & & $\mathrm{x}$ & & \\
\hline Tubino et all (2008) & $\mathrm{x}$ & $\mathrm{x}$ & $\mathrm{x}$ & $\mathrm{x}$ & & & & \\
\hline Mann (2010) & $\mathrm{x}$ & $\mathrm{x}$ & $\mathrm{x}$ & & $\mathrm{x}$ & $\mathrm{x}$ & & $\mathrm{x}$ \\
\hline Tanaka, Muniz Jr e Faria Neto (2012) & $\mathrm{x}$ & $\mathrm{x}$ & $\mathrm{x}$ & $\mathrm{x}$ & & $x$ & $\mathrm{x}$ & $\mathrm{x}$ \\
\hline Quinhões \& Torres Jr (2012) & & $\mathrm{x}$ & & $\mathrm{x}$ & & $\mathrm{x}$ & & \\
\hline Walter e Tubino (2012) & $\mathrm{x}$ & & & $\mathrm{x}$ & & & & \\
\hline Total de Observações Classificadas & 18 & 16 & 15 & 15 & 11 & 10 & 10 & 9 \\
\hline
\end{tabular}

\section{LEGENDA:}

(1) Participação do nível operacional (trabalho em equipe); (2) Capacitação (Conhecimento, Habilidades, Atitudes);

(3) Participação da alta administração (gestão participativa); (4) Aplicação das Técnicas e Ferramentas (melhoria contínua)

(5) Identificar e Eliminar perdas e desperdícios (gemba-processos); (6) Alinhamento com a Estratégia (objetivos, metas, ações, resultados);

(7) Cultura Organizacional (filosofia \& mudança de paradigma/mentalidade); (8) Padronização das atividades, papéis, responsabilidades e disciplina Fonte: Spear e Bowen (1999); Duran e Batocchio (2003); Lucato, Maestrelli e Vieira Jr (2004); Achanga et al (2006);

Feitosa et al (2007); Lorenzato e Ribeiro (2007); Mello (2007); Schulz et al (2007); Alves, Souza e Ferraz (2007); Tanaka, Muniz Jr e Faria Neto (2012); Quinhões e Torres Jr (2012); Nogueira et al (2006); Lima e Elias (2007); 
Godinho Filho e Fernandes (2005); Shingo (1996); Corrêa e Corrêa (2004); Ohno (1997); Imai (1996); Womack, Jones e Roos (2004); Liker (2005); Hines e Taylor (2000); Slack, Chambers e Jonhston (2002); Tubino et al (2008); Ballé e Ballé (2007); Côrrea e Gianesi (1993); Mann (2010); Walter e Tubino (2012).

Mesmo com a classificação das diversas observações dos autores em apenas 8 FCS, o estudo ainda prosseguiu com a sintetização dos FCS encontrados em apenas 3 fatores críticos, são eles: a capacitação, o envolvimento e a cultura.

Constata-se, portanto, que esses três fatores são os que realmente representam a base das problemáticas vivenciada pelos autores pesquisados. Desta forma, formam os pilares que sustentam a etapa inicial do processo de implementação da ME.

A conclusão é que esses três FCS são os que realmente proporcionarão o caminho pelo qual as organizações devem começar a trabalhar para que a ME evolua de forma efetiva e sustentável, conforme mostra a Figura 2.

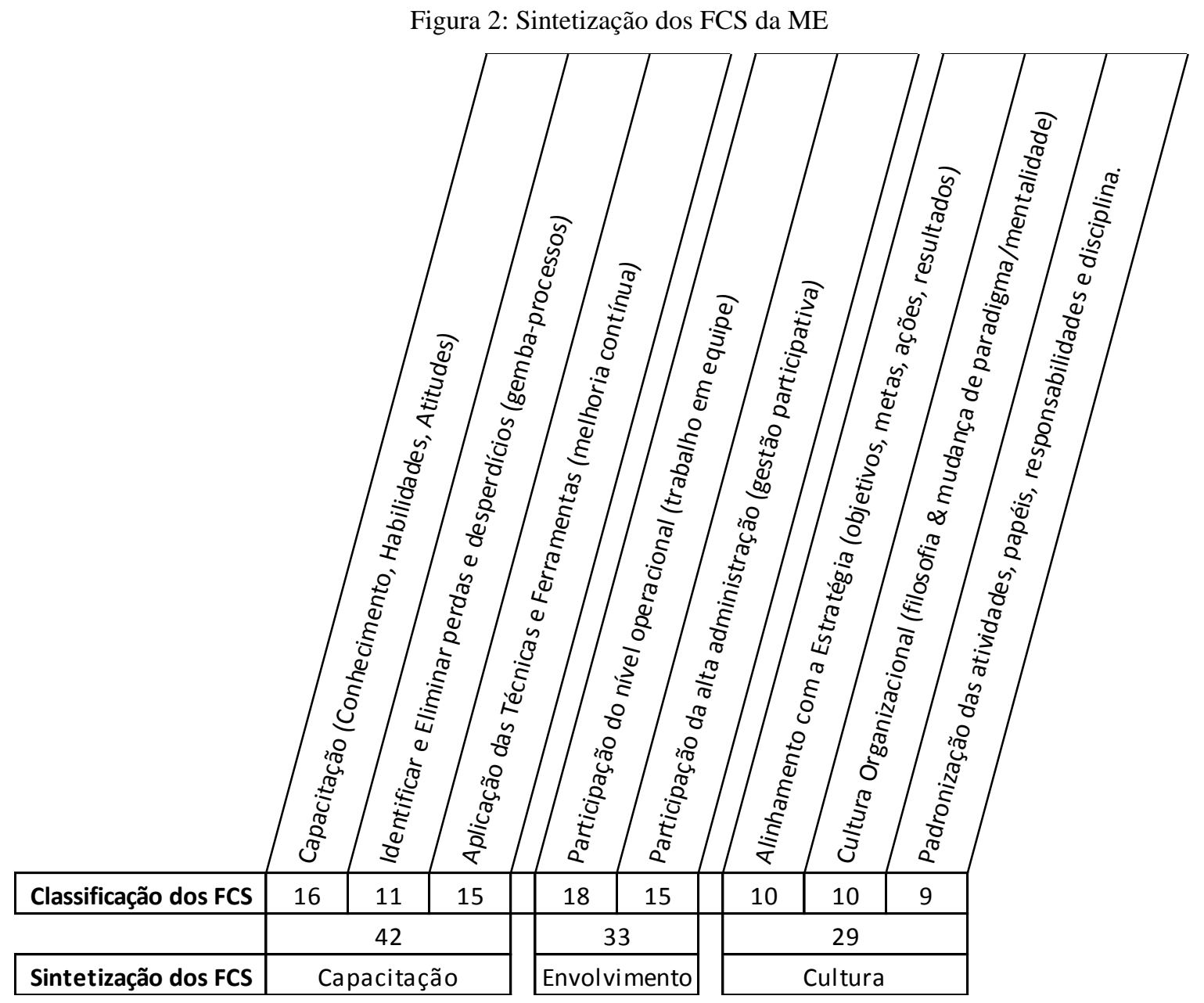

Fonte: Autoria própria (2013)

Percebe-se que somente após uma capacitação adequada das pessoas é possível desenvolver as competências necessárias, a fim de habilitar os colaboradores a identificar as perdas nos processos, bem como a análise e solução de problemas por meio da aplicação adequada das técnicas 
e ferramentas. Também a necessidade da participação efetiva das pessoas, por meio do envolvimento adequado de todos os níveis hierárquicos da organização. Desde o patrocínio constante da alta administração, até o nível operacional.

Após passar pelos dois primeiros FCS, acontece a formação de cultura Lean alinhada com uma estratégia que promove a constante renovação organizacional e que conta com a padronização das atividades, papéis e responsabilidades. Assim como também, a disciplina para a manutenção da evolução da ME de forma sólida e sustentável.

Os trabalhos de classificação e a sintetização também contribuíram para visualizar a relação entre os FCS e as etapas de evolução da ME. Portanto, pode-se concluir que o processo de maturação da ME passa, primariamente, pela capacitação das pessoas, pelo envolvimento adequado destas e, conseqüentemente, com a construção de uma cultura que pensa enxuto.

Desta forma, é correto afirmar que somente após uma capacitação adequada das pessoas, aí sim a ME poderá evoluir e ainda contar com a participação de todos, em todos os níveis e em todas as áreas. O resultado é uma cultura que será transformada pelo pratica e participação de todas as pessoas da organização, sendo também sustentada pelo alinhamento com a visão de futuro da estratégia, conforme a Figura 3.

Figura 3 - Evolução da ME em relação aos FCS



\section{Descrição do FCS: capacitação}

O desenvolvimento humano é o coração da ME, portanto, a essência do sucesso está em capacitar às pessoas a enxergar e eliminar os desperdícios, bem como dar a autonomia necessária para que possam interromper a produção quando necessário. Essa autonomia acaba criando uma conexão entre as elas criando um relacionamento fornecedor-cliente entre uma pessoa e outra, no qual todos acabam sabendo exatamente qual é seu papel no processo produtivo. Entretanto, para que esse processo de dar autonomia seja eficaz, é necessário ensinar um método científico para a análise e solução de problemas, tal como o ciclo PDCA (Plan - planejar; Do - fazer; Check - 
verificar/controlar; Act - agir). Essa capacitação deve alcançar os funcionários de todos os níveis da empresa garantindo que todas as melhorias Kaizen sejam realizadas através de uma metodologia científica, pois, o objetivo principal é ensinar as pessoas de forma prática a solucionar problemas através de uma visão sistêmica e usando repetidos ciclos do PDCA.

O processo de aprendizagem deve ser contínuo, aplicando-se tanto aos supervisores "líderes de equipe" de primeiro nível quanto aos mais altos executivos da empresa que devem atuar como verdadeiros professores. Dessa forma, todos participam do desenvolvimento dos recursos humanos, no qual o ensino segue um caminho top-down (de cima para baixo) começando com o gerente da fábrica treinando todos os funcionários e tomando as medidas necessárias para garantir que todas as operações sejam altamente padronizadas em termos de conteúdo, sequiência, tempo e resultado. Deve-se capacitar as pessoas principalmente estimulando a iniciativa e fazendo com que as mesmas assumam mais responsabilidades.

\section{Descrição do FCS: envolvimento}

Um dos pontos chave da implementação da ME é o total envolvimento de todos, em todas as áreas e em todos os níveis da empresa, desde os membros dos times do chão de fábrica até os gerentes. É preciso motivar as pessoas para que estejam dispostas a dar o seu melhor e ainda melhorar o que já existe dia após dia, pois, o que move os funcionários é a certeza de que é possível fazer mais e melhor a cada dia, o chamado Kaizen (termo japonês para a melhoria contínua). Todas as pessoas devem ser eternos insatisfeitos na busca contínua pela qualidade, um objetivo que se aplica do operário ao presidente e que privilegia o trabalho em equipe.

Entretanto, para que isso aconteça, é necessário desenvolver líderes que realmente entendem o trabalho, praticam a filosofia e ensinam outros, pois desta forma se reconhece as pessoas como um importante recurso da empresa. É por essa razão, que as atividades de gerenciamento devem ter o foco no Gemba, pois, é lá que estão todas as atividades que agregam valor. Portanto, o trabalho dos gerentes deve ser o de dar suporte para os membros das equipes, pois, as equipes prezam o gerenciamento no local de trabalho apenas quando eles podem ver que os gerentes estão lá para ajudá-los a fazerem seu trabalho, não para comandá-los, dizendo o que devem ou não fazer, porque, o exemplo fala mais do que as palavras.

O líder Lean deve liderar pelo exemplo estabelecendo um estilo do tipo "siga-me" ao invés do tipo "faça do meu jeito" ou ainda "faça do seu jeito", pois, a função de liderança não é apenas de simples gerenciadores de tarefas e de manter pessoas com boas habilidades. Os lideres devem ser os modelos da filosofia, portanto, um bom líder deve entender da rotina de trabalho com detalhes, caso contrário, ele não poderá ser o melhor professor da filosofia da empresa. 
A experiência do dia a dia confirma que os líderes tradicionais tentam controlar tudo à distância, baseando-se demais em relatórios e informações imprecisas. Essa forma de liderar acaba afastando o líder cada vez mais do Gemba aumentando ainda mais a sua ignorância. Dessa forma, cria-se um círculo vicioso em que a falta de conhecimento gera uma crescente distância que, por sua vez, aumenta o desconhecimento sobre a real causa dos problemas.

\section{Descrição do FCS: cultura}

A cultura organizacional consiste em padrões explícitos e implícitos de comportamentos adquiridos e transmitidos ao longo do tempo que constituem uma característica própria de cada empresa. Entretanto, para se desenvolver uma característica cultural própria, bem como criar um real diferencial competitivo, é necessário que a empresa mantenha um ambiente uniforme de aprendizado contínuo em toda a organização ano após ano. Agindo dessa forma, a possibilidade de cada pessoa criar a sua própria cultura transformando a empresa em algo superficial no qual não há o desenvolvimento real de lealdade nos funcionários será neutralizada.

Para construir uma cultura que promova a ME irá levar algum tempo, contudo, deve-se desenvolver um correto programa de motivação, caso contrário, será impossível estimular o trabalho em equipe. As pessoas precisam ter um grau de segurança e sentir que pertencem a um time, portanto, faz-se necessário criar tarefas desafiadoras e dar alguma autonomia para que elas possam sentir que têm o controle sobre as tarefas que executam. Também é necessário medir e dar feedback do progresso alcançado, e por ultimo, o merecido reconhecimento. Recomenda-se, no entanto, não implantar times de melhorias antes de fazer um forte trabalho de implementação do sistema e, conseqüentemente, construir a cultura necessária para o sucesso e o suporte que as equipes necessitam para criar ideias que agregam valor.

De acordo com Schein (1985), a cultura organizacional é o desenvolvimento de pressupostos básicos obtidos por um grupo ao aprender como lidar com os problemas de adequação externa e integração interna e que deram resultados satisfatórios para serem considerados válidos e ensinados a novos membros como a forma correta de perceber, pensar e sentir, em relação a esses problemas.

Neste contexto, a cultura de uma empresa passa a ser sua identidade definida como a forma em que seus colaboradores reagem frente aos problemas de adaptação, bem como a maneira de pensar, perceber e agir. Portanto, conclui-se que as pessoas têm papel fundamental no processo de mudança para uma empresa que deseja implantar os princípios da ME.

Segundo Fleury e Fleury (1995), essa ênfase nos processos de mudança obteve destaque com a adoção dos programas de qualidade e produtividade estimulada pelo sucesso do modelo japonês. As empresas das décadas de 1970 e 1980 passaram a privilegiar as técnicas de gestão da manufatura e a reconhecer a importância da cultura organizacional na obtenção do 
comprometimento das pessoas em relação aos procedimentos de mudança. Entretanto, percebe-se hoje que houve certa negligência por parte das empresas, principalmente as ocidentais relacionadas a esse tópico.

O cenário atual é marcado por fortes mudanças que estão virando pelo avesso a maneira de trabalhar, produzir, atender ao cliente, criar valor e agregar riqueza. Por essas razões, a produção de bens e serviços não é mais a mesma. Aparece agora uma empresa enxuta preocupada com uma maior flexibilidade, alta produtividade, estoques baixos, exposição de problemas, menor tempo de entrega produtos e serviços, custos baixos, atividades com valor agregado e pessoas totalmente envolvidas.

Portanto, desenvolver uma cultura organizacional que esteja alinhada com esse novo cenário e perfil organizacional é fundamental não somente para a ME, mas também, como estratégia competitiva sustentável frente à concorrência com o intuito de sobreviver nesse novo ambiente. Para isso, a cultura corporativa deve reforçar a estratégia e o projeto estrutural de que a organização necessita para ser eficaz em seu ambiente. Se o ambiente externo exige flexibilidade e responsabilidade, a cultura deve incentivar a adaptabilidade (MINTZBERG e QUINN, 2006).

A mudança na cultura organizacional das empresas que desejam implantar a ME é necessidade sine qua non, especialmente para aquelas que adotam um modelo de produção em massa. Entretanto, ser Lean está primeiramente em reconhecer que a cultura é formada por pessoas, que estas são os recursos mais importantes de uma organização e, se não for por meio delas, o resultado não aparecerá.

Os colaboradores devem ser estimulados a pensar, fazendo as perguntas certas e nem sempre oferecendo as respostas certas, entretanto, é necessário também criar uma cultura organizacional que possibilite as pessoas a seguir as regras e os padrões estabelecidos como se isso fizesse parte da natureza delas (disciplina). Portanto, considerando que a cultura está inserida nos aspectos críticos da estratégia, desenvolver as pessoas será uma variável de suma importância para a mudança acontecer (MINTZBERG e QUINN, 2006).

\section{Considerações finais}

Não há como negar a demanda atual pela implementação da filosofia do STP. No entanto, implementar com sucesso e de forma sustentável tem sido o grande desafio das organizações. Ocorre que infelizmente a realidade nas organizações é de uma taxa que beira os impressionantes 90\% de insucesso na jornada rumo a ME (WOMACK, 2007).

Neste contexto, por meio dessa pesquisa, foi possível verificar que os vários autores da literatura Lean constataram que vários fatores impedem a implementação da ME nos mais diferentes setores organizacionais. Esses mesmos autores ainda sugerem diversos caminhos a serem 
seguidos como forma de alcançar os resultados desejados. Outros ainda afirmam que é impossível replicar o sucesso da Toyota, pois acham que a cultura não pode ser replicada.

Nessa direção, o estudo realizado concluiu que essas diversidades de observações em relação aos fatores críticos nas organizações, podem causar uma dispersão de ideias sobre qual é a real preparação e o caminho necessário para implantar com sucesso a ME nas empresas. A boa notícia é que a análise realizada na literatura constatou que entre as várias observações dos autores há uma similaridade nas observações. Portanto, podem classificadas de tal forma a dar orientação sobre o caminho a seguir.

Através da identificação, classificação e sintetização dos fatores chave dessas constatações estudadas, foi possível organizar as visões individuais dos pesquisadores, a fim de orientar a todos aqueles que pretendem implantar a ME. O resultado também contribui significativamente para aquelas organizações que porventura ficaram frustradas na tentativa inicial para implementar a ME. Portanto, criando a possibilidade para que essa empresas possam rever suas estratégias a partir dos FCS aqui identificados.

A classificação resultou em uma sintetização de apenas 3 fatores críticos que condensam todas as outras visões estudadas, são elas: a capacitação, o envolvimento e a cultura. Esses fatores encontrados formam os pilares que sustentam a etapa inicial do processo de implantação da ME. Portanto, estabelece o caminho pelo qual as organizações devem começar a implementar a ME.

Contudo, vale lembrar que as empresas que ignoram essa etapa inicial de preparação estão seriamente comprometendo a evolução da ME na organização. Também vale ressaltar que nenhum dos 3 pilares pode ser implementado sozinho e ser esperado que este atinja o nível de sucesso dos 3 fatores combinados, pois a operação combinada desses 3 fatores irá desenvolver o ambiente organizacional apropriado para a evolução da ME em qualquer empresa.

Portanto, conclui-se que o insucesso em replicar o modelo da Toyota está nos primeiros passos em empreender a ME nas empresas, o que consiste em preparar um ambiente organizacional adequado, através do desenvolvimento dos três FCS aqui apresentados. No entanto, o estudo não pretende esgotar a pesquisa sobre os FCS da ME. Vale lembrar que o tempo é o grande colaborador para o avanço do conhecimento científico.

Desta forma, como objeto de novas pesquisas e possibilidade de continuar este trabalho, sugerem-se três possibilidades: (1) a continuidade desse estudo a medida que novos experimentos científicos sejam registrados na literatura do tema, a fim de manter atualizada a classificação dos FCS da ME; (2) a aplicação dos 3 FCS aqui sintetizados como pressupostos estratégicos nas organizações; (3) a transformação dos 3 FCS em indicadores de desempenho, pois sem eles a implementação da ME estará fadada ao fracasso. 


\begin{abstract}
The goal is to identify, classify and summarize the critical success factors (CSF) that prevents organizations to replicate and implement the Toyota Production System, also called Lean Manufacturing. Initially, it developed a brief literature review of the concepts related to the subject. After that, it presents an analysis and classification of the various CSF that hinder the implementation of the Lean. Therefore, a literature in several papers published and making references to obstacles encountered during the process of introduction of Lean. The research reveals that there is a great diversity of representations in relation to critical factors of Lean in organizations, which causes a scattering of ideas about what is really necessary for preparation to introduce successfully the Lean. The findings show that despite this diversity of observations there are commonalities among the factors observed among the authors surveyed, even in areas of different companies. Therefore, the information before scattered in various literatures are now condensed in order to guide organizations on which the CSF that organizations should give focus to the Lean introduction in a consistent and sustainable way.
\end{abstract}

Key-words: critical success factors; toyota production system; lean manufacturing.

\title{
Referências
}

ALVES, F. A.; SOUZA L. G. M. e FERRAZ T. C. P. Identificação de fatores críticos que influenciam o desempenho de projetos de melhoria contínua. In: Encontro Nacional da Engenharia de Produção (ENEGEP), 2007, Foz do Iguaçu. Anais. Foz do Iguaçu: Associação Brasileira de Engenharia de Produção (ABEPRO), 2007.

ACHANGA, P.; SHEHAB, E.; ROY, R. e NELDER, G. Critical Success Factors for Lean Implementation Within SMEs. Journal Manufacturing Technology Management. v. 17, n. 4, p. 460-471, 2006. crossref

AGÊNCIA BRASILEIRA DO ISBN. International Standard Book Number. Disponível em: <http://www.isbn.bn.br/o-que-e-isbn>. Acesso em 18 de agosto de 2013.

BALLÉ, F.; BALLÉ, M. A Mina de Ouro: uma Transformação Lean em Romance. Porto Alegre: Bookman, 2007.

CORRÊA, H. L.; CORRÊA, C. A. Administração da Produção e Operações: Manufatura e Serviços - uma abordagem estratégica. São Paulo: Atlas, 2004.

CÔRREA, H.L.; GIANESI, I.G.N. Just-in-time, MRP II e OPT: um enfoque estratégico. São Paulo: Atlas, 1993.

DURÁN, O.; BATOCCHIO, A. Na Direção da Manufatura Enxuta por meio da J4000 e o LEM. In: Revista Produção online. v. 3, n.2, 2003.

FEITOSA, B. A.; FONTANINI, C. A. C.; WESLEY, V. S. Metodologia Lean Construction Aplicada no Setor de Geração, Transmissão e Distribuição de Energia na Coordenação de Projetos da Construção Civil. In: XXVII Encontro Nacional de Engenharia de Produção, Foz do Iguaçu, PR, Brasil, p. 1- 9, 2007.

FLEURY, A. C. A.; FLEURY, M. T. L. Aprendizagem e inovação organizacional: as experiências de Japão, Coréia e Brasil. São Paulo: Atlas, 1995.

GODINHO FILHO, M.; FERNANDES, F.C.F. Paradigmas Estratégicos de Gestão da Manufatura (PEGEMs): Elementos-chave e Modelo Conceitual. Revista Gestão e Produção. v. 12, n. 3, p. 333 - 345, 2005. cross ref

GODINHO FILHO, M.; FERNANDES, F. C. F. Manufatura Enxuta: uma Revisão que Classifica e Analisa os Trabalhos Apontando Perspectivas de Pesquisas Futuras. Revista Gestão e Produção. v. 11, n. 1, p. 1-19, 2004. crossref

HINES, P.; TAYLOR, D. Guia para implementação da Manufatura Enxuta - "Lean Manufacturing”. São Paulo: IMAM, 2000

IMAI, M. Gemba Kaizen: estratégia e técnicas do Kaizen no piso de fabrica. São Paulo: IMAM. 1996. 
LIKER, J. K. O Modelo Toyota: 14 Princípios de Gestão do Maior Fabricante do Mundo. Porto Alegre: Bookman, 2005.

LIMA, T. C.; ELIAS, B. J. S. Análise dos Resultados da Implantação da Produção Enxuta nas Organizações: um Estudo a partir dos Casos Relatados no ENEGEP. In: XXVII Encontro Nacional de Engenharia de Produção, Foz do Iguaçu, PR, Brasil, p. 1- 9, 2007.

LOREnZATTO, T. J.; RIBEIRO, D. L. J. Projeto de Layout Alinhado às Práticas de Produção Enxuta em uma Empresa Siderúrgica de Grande Porte. In: XXVII Encontro Nacional de Engenharia de Produção, Foz do Iguaçu, PR, Brasil, p. 1- 9, 2007.

LUCATO, W.C.; MAESTRELLI, N.C. e VIEIRA JR., M. Determinação do grau de enxugamento de uma empresa: uma proposta conceitual. In: Encontro da AnPAD, 28, Curitiba, PR, 2004. Disponível em:

<http://www.anpad.org.br/enanpad/2004/dwn/enanpad2004-gol-0647.zip>. Acesso em: 15 dez. 2007.

MACHADO, A. B.; ARAÚJO, R. S. B.; ALONSO, P. S. R.; FERNANDES, E. Avaliação de estratégia e fatores chave de sucesso das pequenas e médias empresas do segmento de petróleo e gás. In: XXVII Encontro Nacional de Engenharia de Produção, Foz do Iguaçu, PR, Brasil, p. 1- 9, 2007.

MELlo CORDEIRO, B. V. J. Sistema Toyota de Produção: Novo Paradigma Produtivo ou Estratégia de Operações?. In: XXVII Encontro Nacional de Engenharia de Produção, Foz do Iguaçu, PR, Brasil, p. 1- $10,2007$.

MINTZBERG, H.; QUINN, J. B. O processo da estratégia. 4 . Ed. Porto Alegre: Bookman, 2006.

NOGUEIRA et al. Identificação dos fatores críticos de sucesso na implantação da filosofia de manufatura enxuta em uma indústria plástica. XIII Simpósio de Engenharia de Produção, Bauru, SP, Brasil, p. 1-11, 2006.

OHNO, T. O Sistema Toyota de Produção - além da produção em larga escala. Porto alegre: Bookman, 1997.

PORTER, M. E. Competição: Estratégias Competitivas Essenciais. Harvard School Business Press, 1999.

QUINHÕES PINTO, A. R.; TORRES JR, S. A. Do TOC à manufatura enxuta. Um estudo de caso de mudança de estratégia. XV Seminários de Administração, São Paulo, SP, Brasil, p. 1 - 17, 2012.

RÉ, T. A. C.; LIMBERGER, J. S.; VIANNA, B. W.; CUNHA, A. C. J. C. O Impacto da Cultura Organizacional no Processo de Gestão do Conhecimento. In: XXVII Encontro Nacional de Engenharia de Produção, Foz do Iguaçu, PR, Brasil, p. 1- 10, 2007.

ROCKART, J. F, Chief Executives Define Their Own Data Needs. Harvard Business Review, v.52, n. 2, pp. 81-93, mar-apr, 1979.

SAE. SAE J4000: Identification and measurement of best practice in implementation of Lean operation. Warrendale, PA, Society of Automotive Engineers, 1999.

SCHEIN, E. H. Organizational Culture and Leadership. São Francisco: Jossey-Bass, 1985.

SCHUlZ, A. A.; ERDMANN, H. R.; CUNHA, H. A.; SANCHES, P. T. As Relações Complexas na Fábrica Enxuta. In: XXVII Encontro Nacional de Engenharia de Produção, Foz do Iguaçu, PR, Brasil, p. 1- 10, 2007.

SHINGO, S. O Sistema Toyota de Produção do ponto de vista da Engenharia de Produção. Porto Alegre: Bookman, 1996.

SLACK, N.; CHAMBERS, S.; JONHSTON, R. Administração da Produção. 2.ed. São Paulo: Atlas, 2002.

SPEAR, S. e BOWEN, H. K. Decoding the DNA of the Toyota production system. Harvard Business Review, Boston: Harvard Business School. v.77, n. 5, p. 97-106, sep. - oct., 1999.

TUBINO, D. F.; SILVA, G. G. M. P.; ANDRADE, G. J. P. O.; HORNBURG, S; OLIVEIRA, L. M. Benchmarking Enxuto: um método de auxílio à implantação da manufatura enxuta. In: XXVIII Encontro Nacional de Engenharia de Produção, Rio de Janeiro, RJ, Brasil, 2008.

TANAKA, Y. W.; MUNIZ JR, J.; FARIA NETO, A. Fatores críticos para implantação de projetos de melhoria contínua 
segundo líderes e consultores industriais. Revista Eletrônica Sistema e Gestão. v. 7, n.1, p. 103-121, 2012. crossref THOMPSON JUNIOR., A. A.; STRICKLAND III, A. J. Planejamento estratégico: elaboração, implementação e execução. São Paulo: Pioneira, 2004.

WALTER, C. F. M. O.; TUBINO, D. F. Avaliação da implantação da manufatura enxuta: uma análise dos anais do ENEGEP. Revista Produção online. Vol. 12, n.3, 2012.

WOMACK, J. P.; JONES, D. T. A Mentalidade Enxuta nas Empresas. $3^{\text {a }}$ ed. Rio de Janeiro: Campus, 2004.

WOMACK, J. P.; JONES, D. T.; ROOS, D. A máquina que mudou o mundo. 14. ed. Rio de Janeiro: Campus, 1992.

WOMACK, J. Das Ferramentas Enxutas (Lean tools) ao Gerenciamento Enxuto (Lean management): a situação da mentalidade enxuta em 2007. Lean Institute Brasil. Artigo. 2007. Disponível em: 〈http://www.Lean.org.br>. Acesso em: 18 ago. 2013.

\section{Dados do autor}

Nome completo: Marcelo Augusto Oliveira da Justa

Filiação institucional: Universidade Federal do Amazonas - Faculdade de Tecnologia

Função ou cargo ocupado: Professor Mestre do Curso de Engenharia da Produção

Endereço completo para correspondência (bairro, cidade, estado, país e CEP): Rua 30, No.19, Quadra A-37, Conj. Jd. de Versalles, Bairro Planalto, CEP 69044-770;

Telefones para contato: 092-91258387 ou 81792273

e-mail: marcelo.justa@bol.com.br

Submetido em: 24/09/2013

Aceito em: 28/08/2014 